\section{Ad futuram Regis memoriam. A história conservativa do túmulo do rei $D$. Dinis: mitos e realidade}

\author{
Ad futuram Regis memoriam. The conservative \\ history of King Dinis' tomb: myths and reality
}

GIULIA ROSSI VAIRO

IEM - Instituto de Estudos Medievais, NOVA - Faculdade de Ciências Sociais e Humanas, Colégio Almada Negreiros, Campus de Campolide, 1070312 Lisboa; CIEBA - Centro de Investigação e Estudos em BelasArtes, FBAUL - Faculdade de Belas-Artes, Lisboa, Portugal grossivairo@fcsh.unl.pt

\begin{abstract}
Resumo
O presente artigo pretende proporcionar, com base na investigação desenvolvida até ao momento, um breve excursus sobre a história conservativa do túmulo do rei D. Dinis, um unicum no panorama da arte portuguesa da primeira metade do século XIV e peça emblemática da escultura medieval europeia.

Por outro lado, o texto questiona algumas afirmações acerca deste tópico transmitidas acriticamente, ao longo dos anos, pela historiografia artística nacional, formulando observações, considerações e raciocínios, baseados na análise e na recognição visual e material da obra, assim como no aprofundamento do contexto histórico de referência.

Nesta perspetiva, o artigo propõe uma revisão da literatura existente sobre os restauros do monumento e, ao mesmo tempo, revisitar o próprio tema do(s) restauro(s) no túmulo, no sentido de quantificar as intervenções e os danos sofridos por este, quer por efeito de catástrofes naturais, quer pela mão do homem.
\end{abstract}

\footnotetext{
Abstract

Based on the research done so far, this paper aims at providing a brief excursus on the conservative history of King Dinis' tomb, a unicum in the Portuguese art scene of the first half of the 14th century and an emblematic piece of medieval European sculpture.

On the other hand, this article calls into question some affirmations transmitted in an uncritical way over the years by Portuguese artistic historiography. Thus, notations, considerations and reasoning are formulated based on the visual and material evaluation of the artwork, as well as on the analysis of the historical context.

The aim is to revisit the existing literature on the restoration of the monument and to quantify the interventions and damage suffered by the tomb, either as a result of natural disasters or by the hand of man.
}

\section{PALAVRAS-CHAVE}

Túmulo do rei D. Dinis Escultura medieval História do Restauro Intervenção de conservação

\section{KEYWORDS}

Tomb of King Dinis Medieval sculpture History of restoration Conservation intervention 


\section{O monumento fúnebre do rei D. Dinis}

O túmulo do rei D. Dinis (Figura I) encontra-se ainda hoje no espaço, embora não no lugar, para o qual foi encomendado, concebido e realizado, isto é, a igreja do antigo mosteiro cisterciense de S. Dinis e S. Bernardo de Odivelas, fundado em finais do século XIII pelo soberano, de acordo com a rainha consorte D. Isabel, e que, anos mais tarde (1318), se tornou no panteão familiar e da Coroa [1].

Executado entre 1318 e 1324, este foi o primeiro sarcófago monumental esculpido para um rei no Portugal medievo, sendo acabado ainda em vida do monarca, que teve, deste modo, a possibilidade de contribuir para a sua concepção e de aprovar o resultado final [2].

Atualmente, o monumento fúnebre compõe-se de uma arca paralelepipédica, decorada nos quatro faciais, assente em seis bases e encimada por uma tampa com jacente. Está lavrado em pedra d'Ançã, clara e branda, e originalmente era completamente pintado, sendo hoje visíveis numerosos vestígios de policromia antiga em todos os elementos que o constituem.

O programa iconográfico, profundamente embebido na espiritualidade cisterciense, desenvolve-se, de forma coerente, desde os suportes até ao jacente. A iconografia celebra as virtudes do rei, príncipe cristão, zelador da fé católica, justo, forte, prudente, leal, simbolizadas nos grupos plásticos dos suportes, e recorda aos fiéis, leigos e religiosos, o caminho a seguir para aspirar à perfeição cristã, promessa de Salvação, inspirando-se no exemplum dos monges e das monjas da ordem, representados dentro de edículas nos faciais maiores da arca, mas também no exemplum do próprio soberano, retratado em oração junto de um presbítero e de joelhos, em atitude humilde, numa edícula do facial menor da cabeceira.

Quanto ao jacente, desconhecem-se a originária efígie do soberano, os atributos que o acompanhavam e até a posição das mãos, uma vez que a estátua, mas também a arca, sofreu diversos e grosseiros restauros ao longo do século XIX cujo objetivo foi reconstruir, mais do que recompor, na tentativa de reparar os estragos provocados pelo terramoto de 1 de Novembro de 1755.

\section{Antigas catástrofes e modernos catastrofistas: o real impacto do terramoto de 1755}

Nas Memórias Paroquiais de 1758, o padre José Lopes Cardoso deu conta da «mayor ruina» causada pelo sismo no mosteiro de S. Dinis e S. Bernardo, quer na igreja, quer no convento, ao referir que a abóbada se abateu sobre o solo, chegando

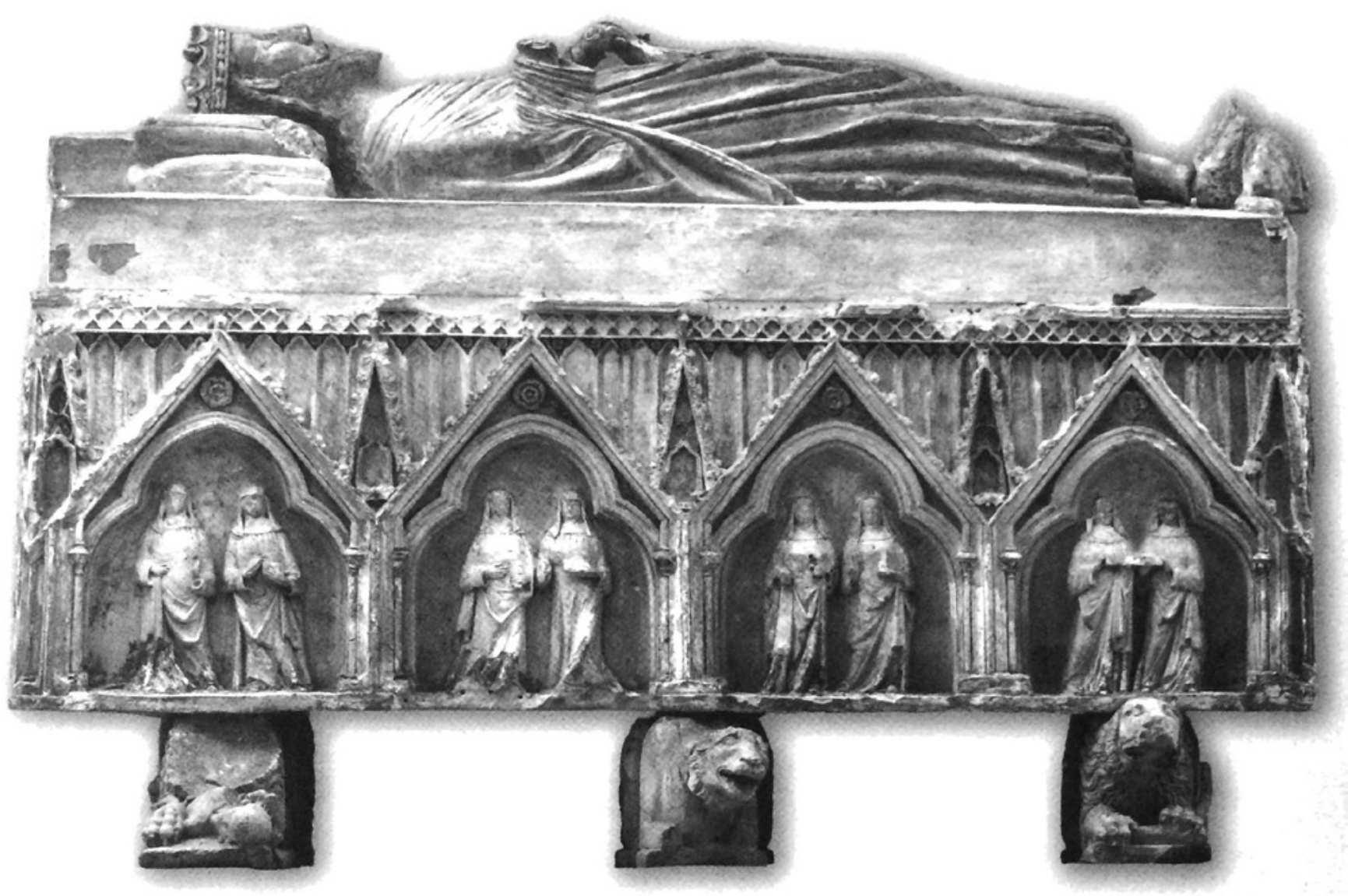

Figura 1. O túmulo do rei D. Dinis. Ortofoto: alçado norte. Fotografia de Sergiy Scheblykin (2017) [3]. 

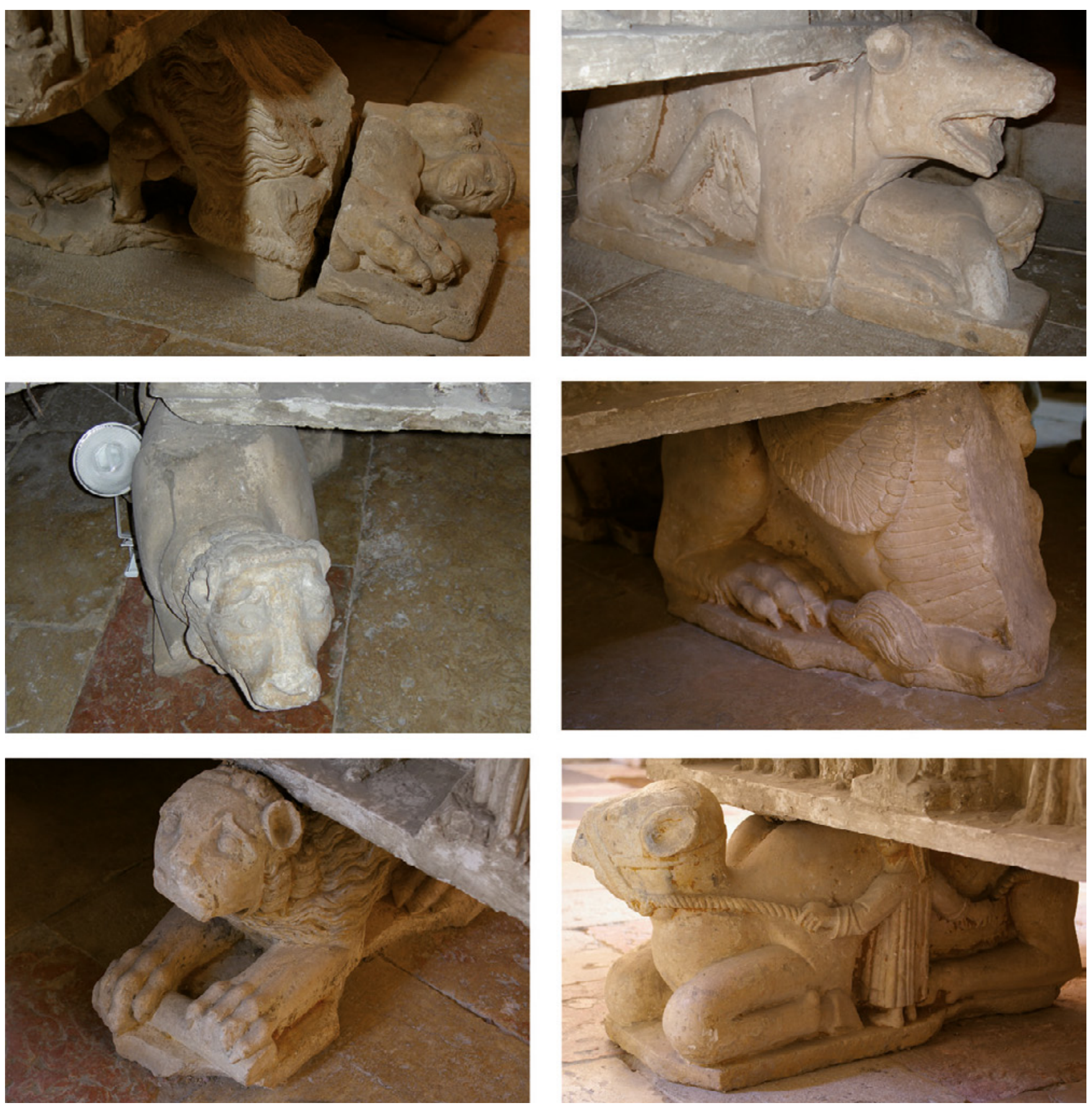

Figura 2. Túmulo do rei D. Dinis, os seis suportes. Odivelas, igreja de S. Dinis.

a matar algumas pessoas presentes. Narrava ainda que no templo conseguiram escapar ao desmoronamento somente a cabeceira, isto é, a capela-mor e os dois absidíolos, e duas capelas no corpo da igreja. Contudo, de acordo com o mesmo relato, ainda em Abril de 1758, dois anos e meio depois do terramoto, não obstante a urgência, nenhuma provisão fora tomada para pôr remédio à destruição, sendo obrigadas as religiosas a acampar dentro da cerca, mas fora dos locais do convento [4].

Assim sendo, é justamente a data do terramoto - 1 de Novembro de 1755 - que neste estudo foi tomada como ponto de partida para o excursus sobre a história conservativa do mausoléu de D. Dinis, pois, efetivamente, aquele trágico evento marcou a "vida" da obra.

Não obstante nas Memórias Paroquiais não se fazer menção ao túmulo, desde 1889 [5], e ao longo dos anos, a historiografia artística tem vindo a reiterar a notícia de que, por ocasião da catástrofe, o teto da igreja colapsou em cima dele, danificando muito especialmente a estátua do soberano. Portanto, mais do que das supostas vandalizações obradas pelas tropas francesas às ordens do comandante Junot, em 1807-1808, durante a primeira fase da Guerra Peninsular, foi na sequência daquele acontecimento, que afetara seriamente a imagem de D. Dinis, que se tornou 


\section{G. R. Vairo}

necessário intervir, de alguma forma, no monumento, para preservá-lo para o futuro.

Não há qualquer dúvida de que o terramoto provocou muitos e graves estragos. No entanto, é este o momento de desvendar o mito à volta destes, ou melhor, redimensionar a natureza e a extensão dos danos. De facto, o colapso do material pétreo da abóbada atingiu sobretudo as partes mais expostas e salientes do monumento e, como tal, mais frágeis, isto é, as bases e o jacente.

Relativamente aos grupos plásticos que atualmente servem de suportes do sarcófago, é preciso especificar que estes são compostos, de acordo com o que chegou até nós, em quatro casos de seis, por animais - dois leões, um cão, um urso, um grifo e um camelo - dominando ou acompanhando figuras humanas. Para quantificar os prejuízos que sofreram por causa do sismo, basta pensar que todos eles se mostram partidos, lacunosos ou mutilados na sua parte anterior, sendo alguns destes (dois) acéfalos ou faltando alguns elementos que garantiriam a sua imediata identificação (Figura 2).

Discurso à parte merece o jacente régio, uma vez que, durante a última visita de estudo à igreja de Odivelas realizada pela autora (Março de 2018), foi possível observar muito de perto as diversas componentes do mausoléu suportes, arca e jacente - que, em finais de 2016, haviam beneficiado de uma intervenção conservativa de limpeza da superfície, executada pela empresa $4 \mathrm{~K}$, resultante de uma pareceria entre a Câmara Municipal de Odivelas e a DireçãoGeral do Património Cultural [6].

O pó e os detritos depositados durante décadas de incúria, à qual atualmente se está a tentar pôr termo, têm sempre impedido uma correta avaliação do estado de conservação da peça, mas a recente intervenção de limpeza tem vindo a "revelar" o túmulo, possibilitando novas leituras e hipóteses interpretativas, a partir justamente da sua análise direta, sem passar através do filtro da espessa camada de sujidade.

Efetivamente, no decurso da visita foi possível averiguar que cerca de $2 / 3$ do jacente se mantêm originais: na efígie, as áreas mais afetadas foram a zona dos braços e a da cabeça, especificamente o rosto, o nariz e a barba, sendo poupados porém a nuca, a fronte até aos olhos, as orelhas e os cabelos. De resto, a figura do rei, que enverga uma túnica coberta por um volumoso e rico manto, movimentado por amplas pregas, apresenta-se com lacunas, desfeita ou em estado fragmentário nalgumas zonas (por exemplo, a dos pés), mas, ao mesmo tempo, autêntica na sua maior parte, permanecendo vestígios da primitiva policromia (azul, vermelho e dourado) na indumentária régia.

Estas observações permitem hoje em dia lançar novas hipóteses acerca das características da original estátua do soberano. Em primeiro lugar, deve destacar-se a marcada desproporção entre a cabeça e o corpo, solução estética deliberadamente procurada pelo mestre responsável, não só em função do ponto de vista dos seus potenciais espectadores, que encarariam a figura numa perspetiva rebaixada, mas

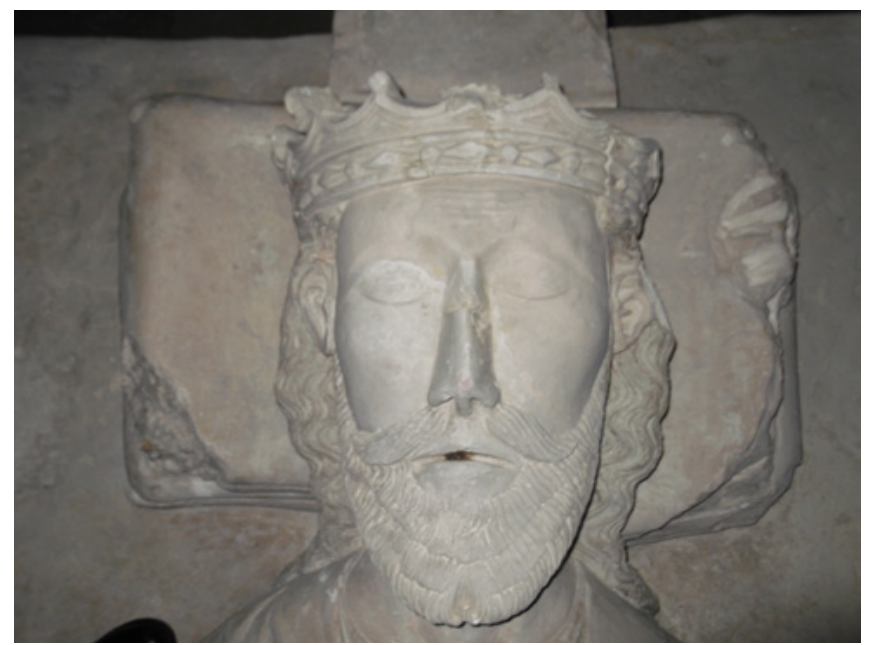

Figura 3. Túmulo do rei D. Dinis, pormenor do jacente. Odivelas, igreja de S. Dinis.

também da mensagem simbólica que esta desconformidade devia transmitir aos seus receptores, uma vez que a imagem esculpida representava o monarca "cabeça do reino".

Acrescente-se que foi possível verificar que, no seu jacente, D. Dinis ostenta olhos fechados, sendo retratado adormecido no "sono eterno" (Figura 3): trata-se de um aspeto totalmente inédito no panorama da escultura funerária portuguesa da primeira metade do século XIV. A esse propósito, vale a pena sublinhar que o próprio rei, que assistiu à execução do seu mausoléu, pôde avaliar e apreciar ainda em vida o resultado final do trabalho escultórico. Sendo assim, o soberano optou por se fazer representar na efígie que teria eternizado a sua memória junto aos vindouros, por um lado envergando a coroa e vestindo a indumentária régia e, por outro, para todos os efeitos cadáver, apanhado na sua humanidade mortal, "adormecido" à espera da Ressurreição. Desta maneira, D. Dinis partilhava o destino de todos os fiéis cristãos do mundo e apresentando-se, simbolicamente, como princeps inter pares.

Esta importantíssima nota iconográfica leva consigo a interrogação, ainda sem resposta, relativa aos atributos que acompanhavam o rei, já que, sendo ele retratado "adormecido", não se explica o porquê do braço direito levantado, como atualmente se apresenta, nem da mão esquerda a segurar uma aba do manto, elementos que resultam dos restauros oitocentistas que alteraram a primitiva imagem do monarca, transformando-a.

Portanto, graças à recente intervenção de conservação, que viabilizou uma leitura mais fiel e correta da iconografia do túmulo e, nomeadamente, do jacente, foi possível redimensionar o real impacto do terramoto de 1755 . Por outro lado, deve ser considerado que, já naquela altura, o sarcófago devia apresentar alguns problemas do ponto de vista estrutural, consequência das movimentações de que o mausoléu foi alvo entre o século XVI e XVII. De facto, originalmente, de acordo com as disposições testamentárias do soberano, o sepulcro estava posicionado 


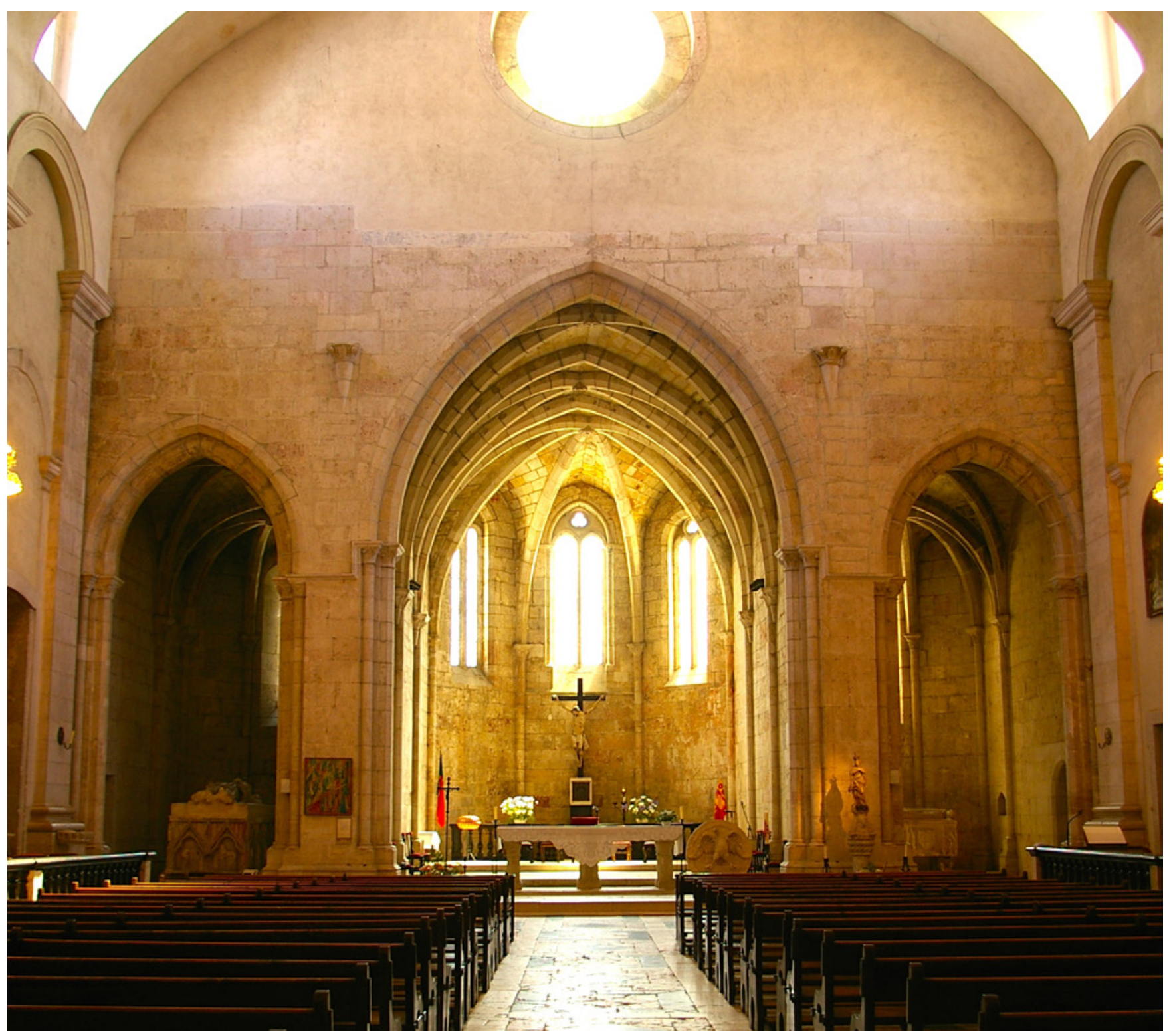

Figura 4. Atual colocação do túmulo do rei D. Dinis. Odivelas, igreja de S. Dinis, capela do Evangelho.

no meio da igreja, entre o coro e a capela-mor [7]. Contudo, em meados do século XVII, encontrava-se, não no centro, mas na nave "à banda da epístola", isto é, em frente da sacristia, como refere o padre George Cardoso no Agiologio Lusitano (1652) [8]. Acrescente-se que, nas centúrias seguintes, o monumento literalmente "circulou" no espaço eclesiástico, acabando por ser enfiado no absidíolo do Evangelho onde ainda hoje está localizado, sendo esta uma colocação que afeta a sua fruição estética, desvaloriza a sua função originária dentro da igreja, para além de desconsiderar a vontade do soberano (Figura 4) [9].

Todas as movimentações que o mausoléu sofreu (algumas, como vimos, bem anteriores ao sismo de 1755) prejudicaram a integridade da peça: basta olhar para o estado de conservação da orla da arca, desfeita e partida, para compreender o tipo de dano provocado pelas contínuas transladações (Figura 5). Ao mesmo tempo, numa leitura a posteriori dos acontecimentos, pode inferir-se que foi talvez

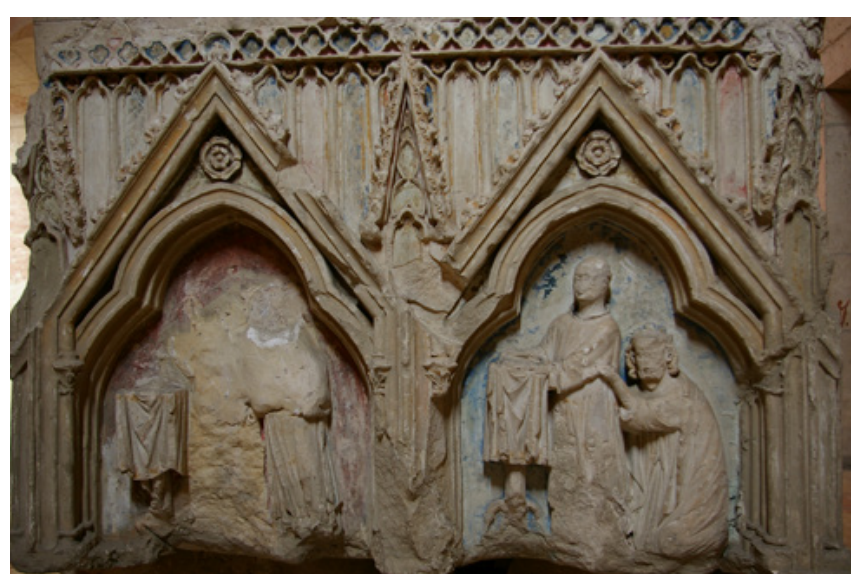

Figura 5. Túmulo do rei D. Dinis, pormenor de um dos lados breves e do estado de conservação da orla da arca. Odivelas, igreja de S. Dinis. 
justamente a transferência, atuada a pedido das monjas, para um lugar mais recuado (a referida capela) que livrou o túmulo da destruição total.

\section{Atos vandálicos e malfeitorias: o impacto da intervenção humana}

De acordo com esta análise, pode até parecer que a arca passou incólume ao terramoto, afirmação que, porém, contrasta com o aspeto dos quatro frontais do túmulo. De facto, as imagens inseridas em pares dentro das edículas que marcam o ritmo dos faciais (doze na totalidade) apresentam-se em condições bastante precárias: os monges são todos acéfalos (Figura 6a); as monjas são completamente reconstruídas na parte superior do corpo, mostrando as integrações em gesso posteriores à sua primitiva execução (Figura 6b); as outras figuras de religiosos ainda perceptíveis - um presbítero e um abade acompanhado por um acólito (Figura 7) - encontram-se bastante danificados ou mutilados; das outras personagens presentes são reconhecíveis somente os padrões deixados na superfície da pedra.

Neste quadro, a única figura que permanece legível e ainda relativamente íntegra é a do rei, retratado num dos faciais menores de joelhos e ao lado de um presbítero igualmente em boas condições (Figura 5).

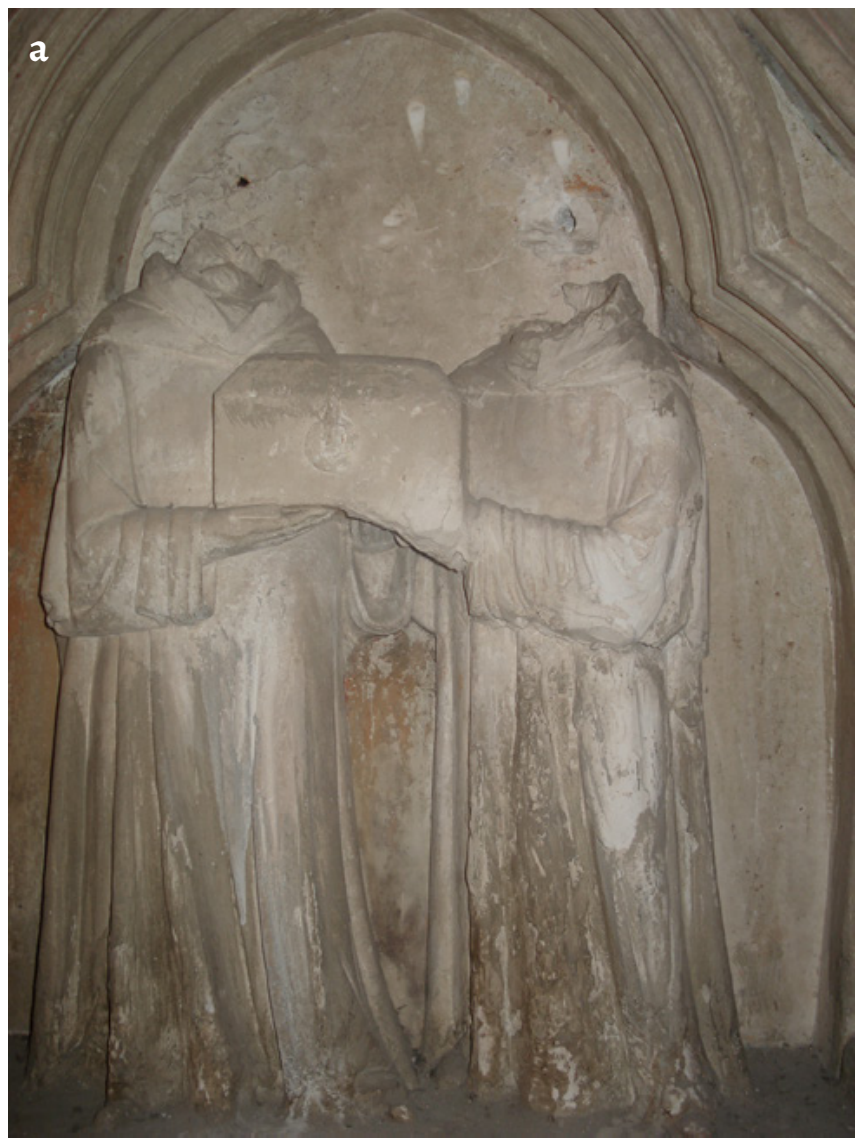

Efetivamente, não se pode de todo excluir que também a arca tenha sofrido graves estragos devido ao sismo, tal como discutido na secção anterior. Não obstante, ao estudar a história e as vicissitudes da obra e ao observá-la de perto, pode-se inferir que o que mais provocou danos foi a mão dos homens, todos os que nesta atuaram motivados quer por maus quer por bons propósitos. Pensa-se, nomeadamente, por um lado nos atos vandálicos de que foi alvo o mausoléu dionisino e cuja responsabilidade a historiografia tem vindo a atribuir ao espírito anticlerical e à cobiça das tropas francesas [10]; e, por outro, nos restauros oitocentistas que intervieram de forma pesada e não filológica, quer no jacente, quer nos faciais, sobretudo naquele onde encontramos as imagens das monjas.

Relativamente às vandalizações, crê-se que os responsáveis não foram necessariamente os militares sob o comando do General Junot, pois variadas são as circunstâncias que suscitam perplexidades a respeito desta eventualidade.

Em primeiro lugar, na altura, Odivelas, que então pertencia ao concelho de Loures, não era mais do que uma pequena e anónima vila rural, apta às excursões dominicais da alta sociedade lisboeta pela paisagem amena, mas decididamente fora de mão para os itinerários estratégicos das tropas de passagem, representando um desvio no caminho em direção a Santarém-Torres Vedras. Além disso, há dificuldade em crer que os soldados tivessem

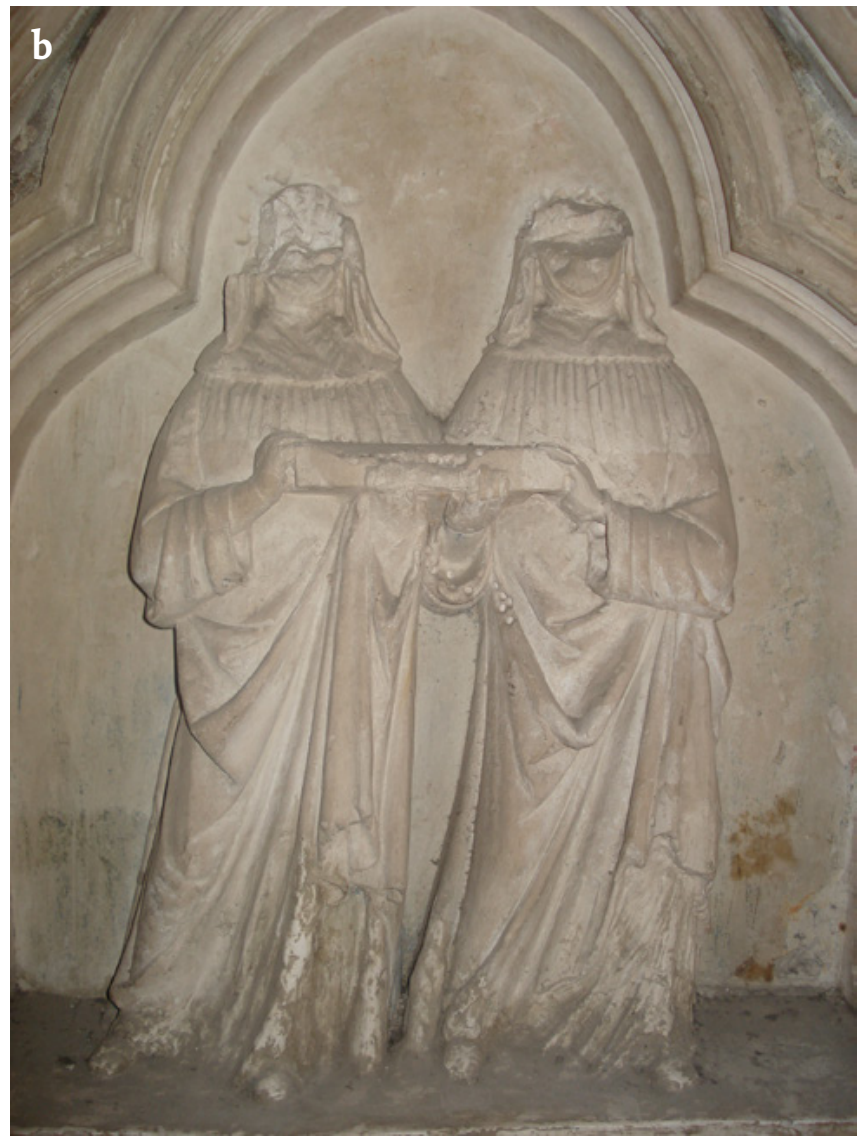

Figura 6. Túmulo do rei D. Dinis, detalhes da decoração da arca: a) monges e b) monjas. Odivelas, igreja de S. Dinis. 


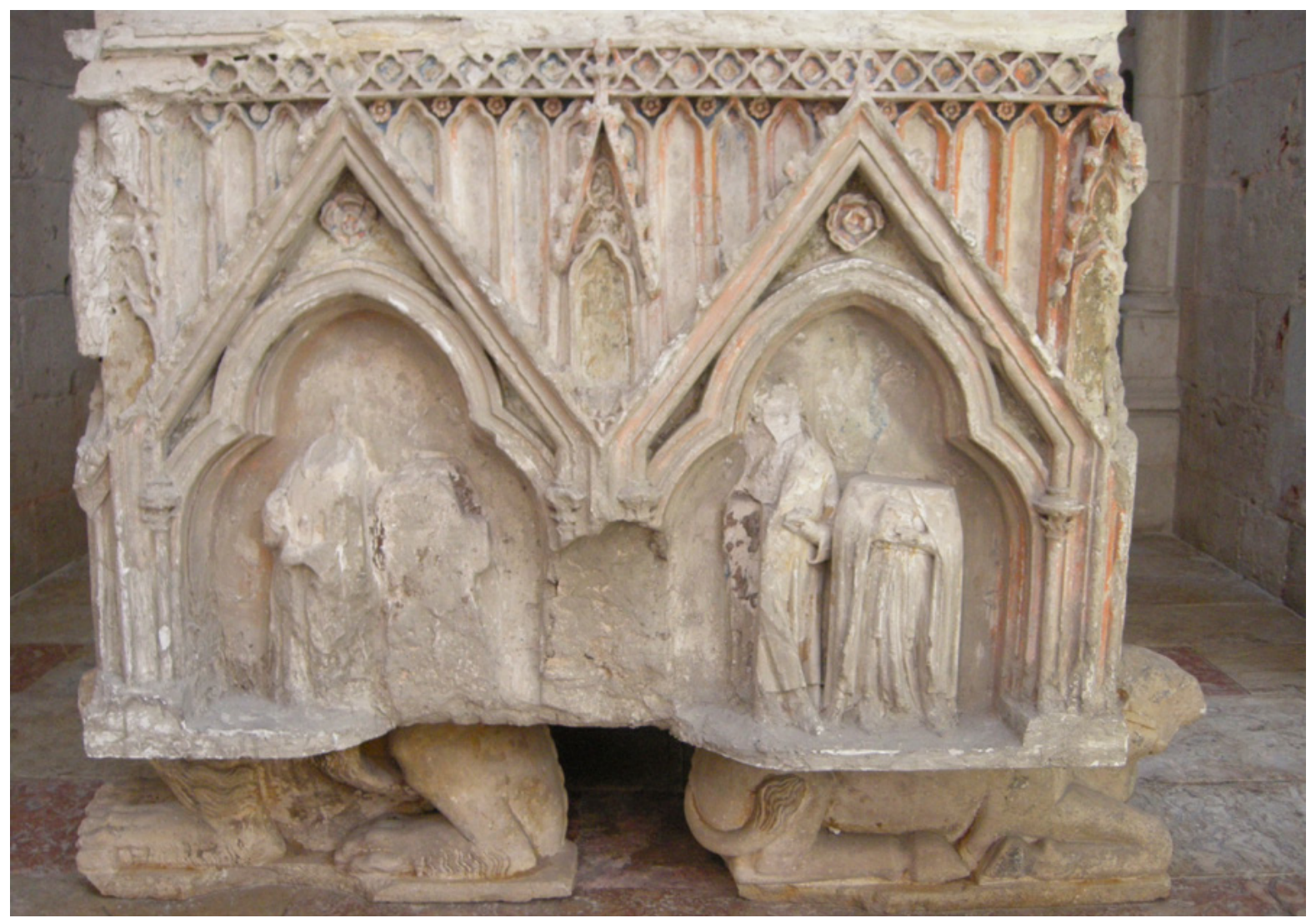

Figura 7. Túmulo do rei D. Dinis, pormenor de um dos lados breves e do estado de conservação da orla da arca. Odivelas, igreja de S. Dinis.

conhecimento da existência de um mosteiro em Odivelas ainda por cima sendo de monjas - onde se guardava o corpo de um soberano.

Por outro lado, vale a pena salientar que a arca não mostra as "cicatrizes" típicas da profanação operada pelos militares à procura de tesouros: pense-se, por exemplo, nas marcas deixadas nos sarcófagos de D. Pedro I e de D. Inês de Castro, no mosteiro de Santa Maria, em Alcobaça, ou no monumento do rei D. Fernando, hoje no Museu Arqueológico do Carmo, em Lisboa.

A verdade é que a caixa pétrea, mesmo que muito desfeita, se encontra inteira, e que, aquando da primeira abertura documentada do sarcófago, em 1938, altura em que se partiu a tampa, destruindo o friso de coroamento, a caveira e os ossos de D. Dinis ainda lá estavam [11] (e ainda lá se encontram!), juntamente com alguns fragmentos de tecidos preciosos [12], não tendo sido objeto de ultrajes e dispersão como foi no caso dos despojos dos monarcas franceses. Igualmente, o outro túmulo presente na igreja, o do infante D. Dinis, neto do rei D. Dinis, está perfeitamente íntegro, não apresentando qualquer sinal de corrupção, tendo sido alvo de vandalizações sim, mas em tempos mais recentes, como os grafitos - datados de 1967 - na superfície do monumento denunciam. Finalmente, convém enfatizar que a única figura que ainda se conserva inteira, como já foi recordado, é a do soberano: se o sepulcro tivesse sido objeto das "atenções" dos napoleónicos, esta não teria escapado à fúria iconoclasta francesa.
Para além disso, temos um testemunho de exceção que nos informa acerca do estado do mausoléu em finais dos anos 20 do século XIX: trata-se do poeta, escritor e dramaturgo João Baptista da Silva Leitão de Almeida Garrett, pioneiro da salvaguarda do património cultural e monumental da Nação portuguesa [13], que, na sua obra Lyrica de João Mínimo de 1829 [14], dá conta da visita feita à igreja de Odivelas.

Nesta ocasião, o autor lamenta o estado miserável de abandono em que achara o templo e o sepulcro régio. Relativamente a este último, envolto pela obscuridade e muito danificado, Almeida Garrett expressa-se em termos de «desfigurado, mascarado, emplastado da ignorância e perverso gosto d'estes monges das idades bárbaras», definidos como «vândalos» e fazendo referência à atualidade. Não obstante, o poeta refere a presença de uma inscrição em caracteres góticos na orla superior da arca, hoje não visível, e afirma que o frontal dos monges mantinha a sua antiga feição, ao contrário do das monjas, já na altura grosseiramente intervencionado.

À luz deste relato, aprendemos que a mutilação das cabeças dos monges ocorreu posteriormente, e que o restauro das monjas foi realizado antes de 1829 de uma forma não mimética, perfeitamente reconhecível a olho nu ainda hoje, sendo como tal, em princípio, reversível.

A descrição de Almeida Garrett encontra confirmação na litografia do gravador da Costa, tirada de um desenho "ao vivo" de Manuel Bordalo Pinheiro, publicada no Jornal das Belas Artes, revista que só chegou a ser impressa no biénio 1843-44 [15]. 
Mesmo admitindo a eventualidade de alguns acrescentos fruto da criatividade do pintor, pode-se afirmar que estamos perante aquele que deve ser considerado como o primeiro testemunho iconográfico do túmulo dionisino de que dispomos, pelo menos até agora, que contém muitos dados verídicos e bem documenta o estado de conservação da peça na altura.

Entre as muitas anotações que se poderiam registar refletindo sobre esta ilustração, a começar pela iconografia do jacente, que se apresenta de barba curta, de mãos postas e sem espada ou cetro, merece ser destacada a presença de ornamentação no coroamento da arca e as figuras dos monges - as mais visualmente perceptíveis, devido à sua colocação - que, ao contrário de como surgem atualmente, se apresentavam inteiras, tendo sido reproduzidas justamente por esta razão.

Este era o aspeto do sarcófago ainda em 1862, acabado de sair de um restauro, mandado realizar por ordem da rainha D. Estefânia, mulher do rei D. Pedro V [16], se acreditarmos no texto do artigo sem título e não assinado, mas de autoria de Ignácio Vilhena Barbosa, publicado no Arquivo Pitoresco [17] e acompanhado por uma litografia tirada de um desenho de Nogueira da Silva, muito parecida com a de Bordalo Pinheiro, todavia não idêntica (Figura 8).

Assim sendo, o monumento foi objeto de outros atos vandálicos, nomeadamente no frontal dos monges, provavelmente obra de "vândalos indígenos", visitantes ocasionais ou locais, a seguir a 1862, numa altura em que a exígua comunidade monástica já não conseguia controlar o acesso à igreja e ao convento e vigiar sobre o seu património.

Após esta data, seguiu outro restauro que foi possível detectar através do estudo de fontes indiretas e diretas, mesmo que muito sucintas (entre 1887 e 1895) [18]. Contudo, a intervenção que alterou para sempre a imagem do rei, não correspondendo àquela que o próprio D. Dinis aprovara para que fosse transmitida aos vindouros, foi executada entre 1862 e 1886.

Neste caso, não dispomos de registo documental, mas exclusivamente gráfico, pois dá testemunho da transformação atuada a litografia de Caetano Alberto publicada na revista Occidente, em 1886 [19]: aqui o soberano já surge de barba longa e envergando uma coroa radiada ambos detalhes reconstruídos em gesso e que faltavam na imagem de Bordalo Pinheiro - e de braços suspensos no ar, como atualmente o podemos ver (Figura 9).

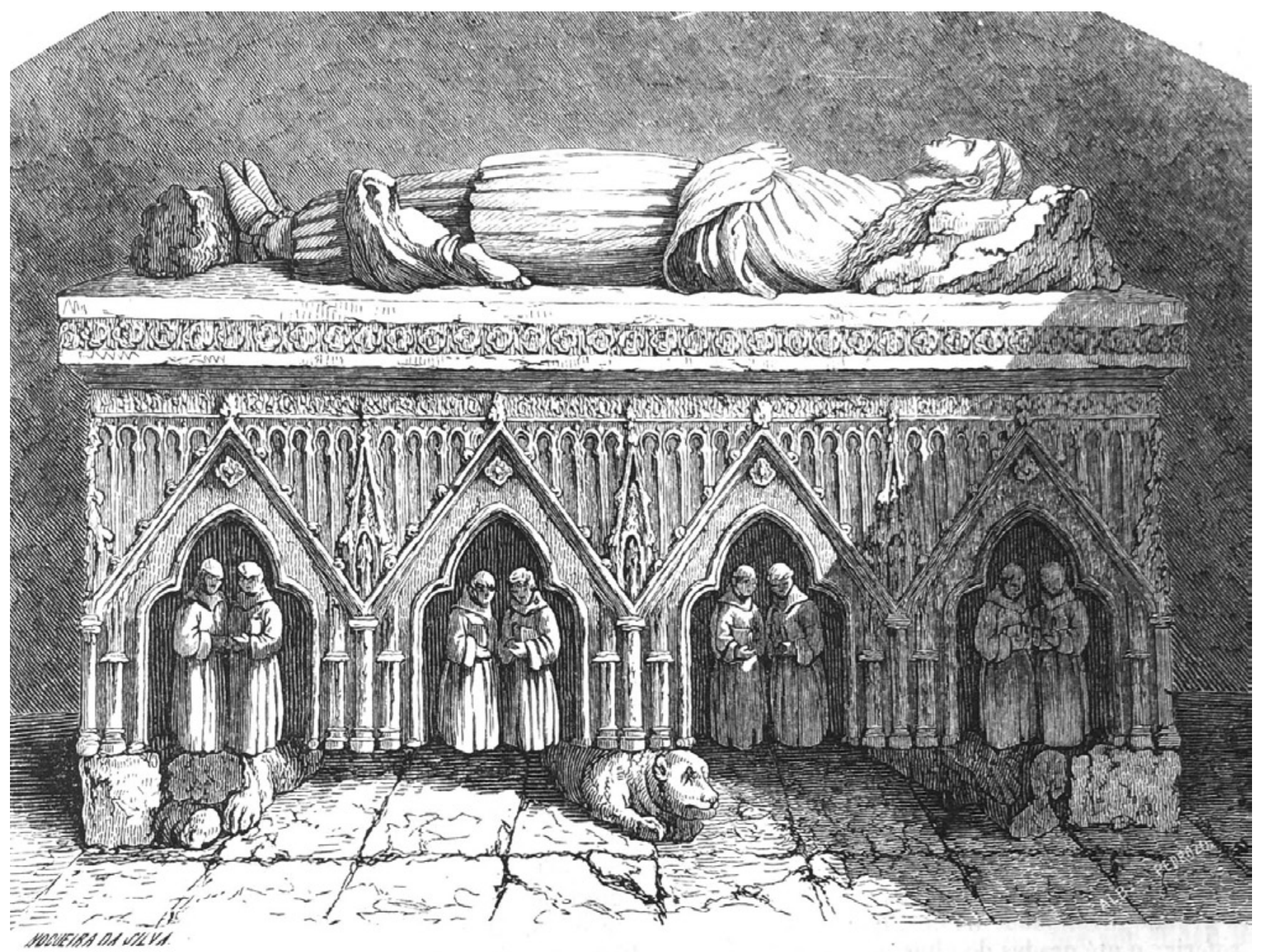

Figura 8. Túmulo do rei D. Dinis. Arquivo Pitoresco, 1862. Litografia de Nogueira da Silva. 


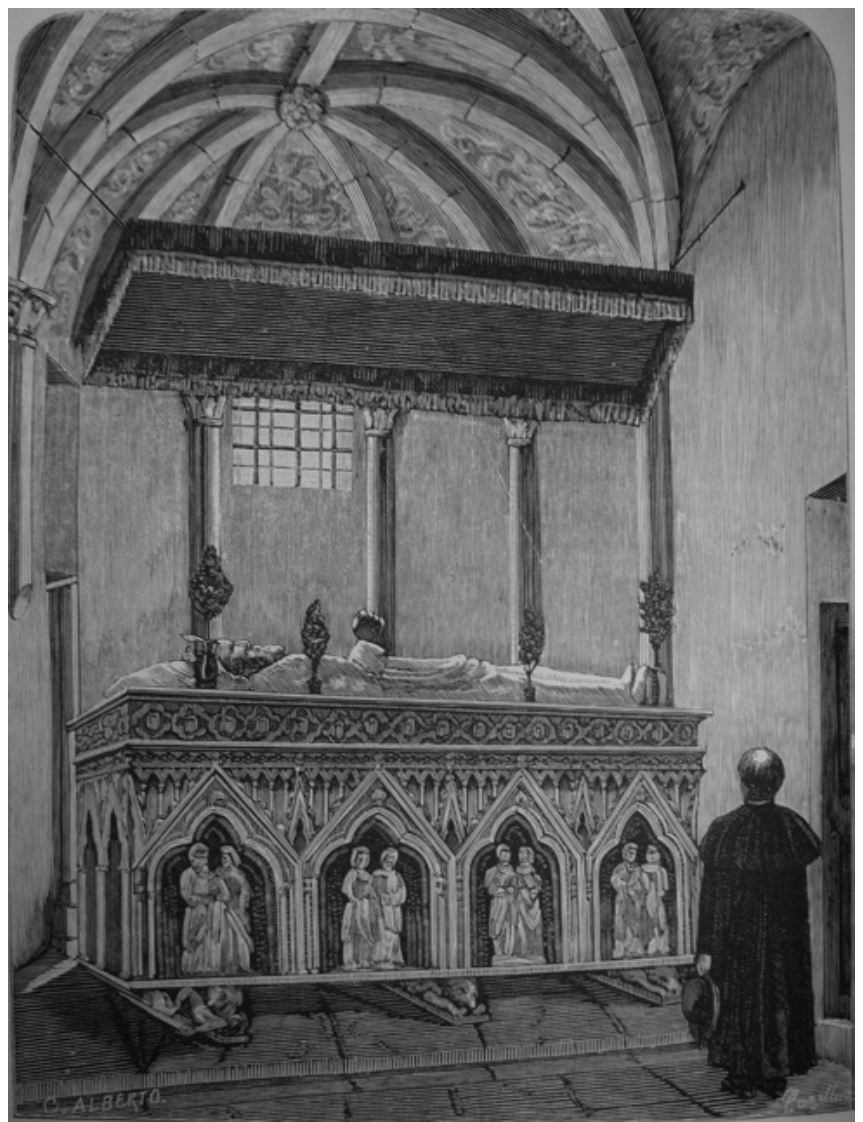

Figura 9. Túmulo do rei D. Dinis. O Occidente, 1886. Litografia de Caetano Alberto

\section{Conclusões}

Ao longo deste artigo foi dado conta dos resultados da investigação até hoje desenvolvida sobre a história conservativa do túmulo de D. Dinis, focando-se sobretudo nos efeitos das intervenções oitocentistas, até aqui não identificadas ou superficialmente tidas em consideração. Contudo, foram apresentados, de forma sistematizada, somente os primeiros resultados da pesquisa, tratando-se de um work in progress, realizado no âmbito do projeto intitulado Ad futuram Regis memoriam: o restauro do túmulo do rei D. Dinis, enquadrado no Programa de trabalhos de PósDoutoramento da autora deste texto [20].

Em extrema síntese, o projeto Ad futuram Regis memoriam: o restauro do túmulo do rei $D$. Dinis pretende proporcionar a um público de especialistas e não especialistas um estudo histórico-artístico, resultante da investigação histórica, arquivística, iconográfica, estilística e formal sobre o monumento fúnebre do rei D. Dinis, consagrando uma especial atenção à sua história conservativa, aos restauros executados e àqueles ainda por fazer.

O objetivo final deste trabalho é contribuir para a definitiva recuperação da memória, valorização e desejável, embora parcial, musealização desta obra-prima da escultura medieval portuguesa, uma vez que um estudo científico, rigoroso e aprofundado, constitui sempre o primeiro passo para a dignificação de uma obra de arte, qualquer que ela seja.

Nomeadamente, o estudo sobre a história conservativa do mausoléu de D. Dinis deve continuar, visando uma quantificação, o aprofundamento e a definição da substância e da consistência de todas as intervenções, tendo em conta a quase total ausência de relatórios manuscritos na prática do restauro durante o século XIX.

Nesta perspetiva, seria desejável cruzar as informações deduzidas da investigação histórico-artística e da análise objetiva da peça com os dados surgidos dos exames de diagnóstico efetuados durante a campanha de intervenção de finais de 2016 e inícios de 2017, pois na metodologia subjacente à teoria e à pratica do restauro do século XXI é - ou deveria ser - imprescindível o diálogo, a interdisciplinaridade, a partilha e a troca de informações entre historiadores de arte e os responsáveis do sector da Conservação e Restauro, só para mencionar as primeiras duas categorias profissionais, mas não as únicas, envolvidas neste tipo de trabalho.

De facto, para conceber, hoje, um projeto de valorização realmente eficaz para o monumento fúnebre do rei $\mathrm{D}$. Dinis, que contemple ações de restauro e de musealização, antes de tudo é preciso conhecer: conhecer para restituir à obra a sua dignidade histórica e histórico-artística, conhecer para melhor poder compreender, acompanhar e promover novas intervenções conservativas, conhecer para preservar para o futuro.

\section{Agradecimentos}

A autora gostaria de agradecer o financiamento da Fundação para a Ciência e a Tecnologia, através da bolsa de Pós-Doutoramento: "O Mosteiro de S. Dinis de Odivelas, memória do País: o Monumento e o Património" (SFRH/ BPD/108772/2015), sob a orientação do Prof. Dr. Bernardo Vasconcelos e Sousa, IEM, FCSH/UNL e a coorientação do Prof. Dr. Fernando António Baptista Pereira, CIEBA, FBAUL.

\section{REFERÊNCIAS}

1. Rossi Vairo, G., 'D. Dinis del Portogallo e Isabel d'Aragona in vita e in morte. Creazione e trasmissione della memoria nel contesto storico e artistico europeo', Tese de Doutoramento em História da Arte Medieval, Faculdade de Ciências Sociais e Humanas, Universidade Nova de Lisboa, Lisboa (2014).

2. Rossi Vairo, G., 'Un caso emblematico (e dimenticato) della scultura funeraria trecentesca europea: il monumento funebre del re Dinis di Portogallo (1279-1325)', Arte Medievale VII (2017) 167-192.

3. Os túmulos de D. Dinis e do Infante. Um Novo Olhar, catálogo da exposição, Câmara Municipal de Odivelas, Odivelas (2017).

4. Arquivo Nacional da Torre do Tombo (ANTT), Memórias Paroquiais de 1758, fls. 59-69.

5. Borges de Figueiredo, A., O Mosteiro de Odivelas. Casos de reis e memórias de freiras, Livraria Ferreira, Lisboa (1889).

6. $4 \mathrm{~K}$ - Wilton Trindade, S., Relatório da intervenção dos túmulos de D. Dinis e do Infante na Igreja do Mosteiro de São Dinis e São 


\section{G. R. Vairo}

Bernardo em Odivelas, Lisboa (2017).

7. Sousa, A. C., Provas da História genealógica da Casa real portuguesa, Atlântida - Livraria Editora, Coimbra (1946-1957).

8. Cardoso, G., Agiológio Lusitano, Officina Craesbeekiana, Lisboa (1652).

9. Rossi Vairo, G., 'Um caso de "circulação" e "transformação" de património integrado: o túmulo do rei D. Dinis', in Dinâmicas do Património Artístico. Circulações, Transformações e Diálogo, eds. C. Moura Soares \& V. Mariz, ARTIS - Instituto de História da Arte da Faculdade de Letras da Universidade de Lisboa, Lisboa (2018) 295-303.

10. Cordeiro de Sousa, J. M., 'Malfeitorias no túmulo do rei dom Dinis', Revista de Guimarães 76(1966) 2-7.

11. 'O corpo do rei D. Deniz encontra-se ainda no seu túmulo de Odivelas', O Século, 16 de maio de 1938.

12. Matos Sequeira, G., 'O pano de seda da mortalha do rei $D$. Deniz é um precioso documento têxtil do século XIV', O Século, 2 de Junho de 1938.

13. Soares Moura, C.; Neto, M. J., Almeida Garrett: a 'Viagem' e o Património, Caleidoscópio, Lisboa (2015).

14. Almeida Garrett, J., Lyrica de João Mínimo. Publicada pelo auctor do resummo de Historia, de Lingua e Poesia Portugueza, do Poema Camões, D. Branca, Adozinda, etc., Sustenance e Stretch, London (1829).
15. Jornal das Belas Artes s. n. (1843-44) 38.

16. Cordeiro de Sousa, J. M., 'Malfeitorias no túmulo do rei dom Dinis', Revista de Guimarães, 76(1966) 5.

17. Arquivo Pitoresco 5(1862) 77-79.

18. ANTT, Ministério das Obras Públicas, Comércio e Indústria, maço 442, 10: Restauração do túmulo d'El-Rei D. Dinis no convento de Odivellas (1895, Agosto, 12, Lisboa).

19. Barbosa Vilhena, I., 'Crónica de Odivellas', O Occidente, 9(278) (1886) 203-204.

RECEBIDO: 2018.12 .10

REVISTO: 2019.12.5

ACEITE: 2020.2.13

ONLINE: 2020.5 .30

\section{(c) (1) (3)}

Licenciado sob uma Licença Creative Commons Atribuição-NãoComercial-SemDerivações 4.0 Internacional. Para ver uma cópia desta licença, visite http://creativecommons.org/licenses/by-nc-nd/4.o/deed.pt. 